Preprints of the

Max Planck Institute for

Research on Collective Goods

Bonn 2013/5

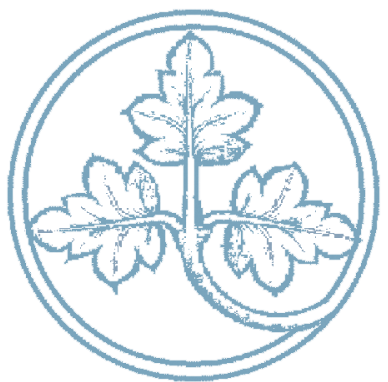

Selfishness As a Potential

Cause of Crime

A Prison Experiment

Thorsten Chmura

Christoph Engel

Markus Englerth

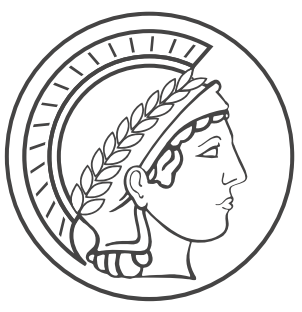




\section{Selfishness As a Potential Cause of Crime A Prison Experiment}

Thorsten Chmura / Christoph Engel / Markus Englerth

March 2013 


\title{
Selfishness As a Potential Cause of Crime A Prison Experiment
}

\section{Thorsten Chmura / Christoph Engel / Markus Englerth}

\begin{abstract}
For a rational choice theorist, the absence of crime is more difficult to explain than its presence. Arguably, the expected value of criminal sanctions, i.e. the product of severity times certainty, is often below the expected benefit. We rely on a standard theory from behavioral economics, inequity aversion, to offer an explanation. This theory could also explain how imperfect criminal sanctions deter crime. The critical component of the theory is aversion against outperforming others. To test this theory, we exploit that it posits inequity aversion to be a personality trait. We can therefore test it in a very simple standard game. Inequity averse individuals give a fraction of their endowment to another anonymous, unendowed participant. We have prisoners play this game, and compare results to findings from a meta-study of more than 100 dictator games with non-prisoners. Surprisingly, results do not differ, not even if we only compare with other dictator games among close-knit groups. To exclude social proximity as an explanation, we retest prisoners on a second dictator game where the recipient is a charity. Prisoners give more, not less.
\end{abstract}

JEL: A12, C91, C93, D03, D63, K14

Keywords: crime, imperfect sanctions, selfishness, inequity aversion, dictator game, social proximity, charity

Helpful comments by Kristoffel Grechenig and Michael Kurschilgen on an earlier version are gratefully acknowledged. 


\section{Research Question}

Most people do not steal, trespass, blackmail, assault, rape or kill. For a rational choice theorist of crime (for a survey see Eide et al. 2006), explaining these observations is not obvious. Of course, some people may not derive any benefit from committing some of these crimes. Yet it is rare that a person finds additional money unattractive. Most young men would also find more sex appealing. If they cannot deny the benefit, rational choice theorists must find a cost. This cost can be an out-of-pocket cost. For the would-be criminal, breaking into a house can require so much effort that it is not worth the while (McCarthy and Hagan 2001). The individual may dread extra-legal consequences, like social sanctions (Nagin and Pogarsky 2001), the revenge of victims (Jacobs et al. 2000), or the loss of future opportunities for earning a legal income (Grogger 1998). The threat of legal sanctions may be sufficiently powerful. If the individual holds standard preferences, this requires that the product of the expected severity of the sanction, multiplied by the probability of enforcement, exceeds the benefit from crime (Becker 1968; Levitt 2004). The cost can also be an opportunity cost. In the legal economy, the individual can make more money at a lower cost or risk (Levitt and Venkatesh 2000).

In this perspective, crime is unrelated to personality. An individual does not commit crime because she has bad character. A personality trait that most people in the street would expect to be correlated with crime does not feature in the standard rational choice approach to crime. People are not more likely to be criminal because they are more selfish than others. Actually, in the world of the rational choice theorist, everybody is selfish, in the sense that she maximizes her given preferences. If she holds "standard preferences", she cares about other peoples' preferences, but only in the interest of anticipating their reactions to her own action. Because rational choice theory assumes everybody does, social interaction constitutes games that lend themselves to the precise calculation of equilibria (for a survey of applications to the analysis of crime see McCarthy 2002).

Rational choice theory is not confined to economics, and may be applied to activities as uneconomical as hijacking an aircraft (Dugan et al. 2005) or molesting a woman (Bachman et al. 1992). Yet while the rational choice approach isn't but one of many competing paradigms in disciplines like political science, sociology, or criminology for that matter, it is the core of economics. Microeconomic theory wants to be applied to any individual activity, whether or not there is a good or service to be traded on a market, and whether or not explicit prices are in use (Becker 1976; Becker 1996). This explains why the debate over the limitations inherent in textbook rational choice models is most vigorous in economics. Over decades, this debate has been fuelled by testing formal economic models in the lab (see only Smith 1976; Selten 1998). In this endeavor, experimental economists have closely collaborated with social psychologists (for an overview see Kahneman and Tversky 2000).

In some institutional settings, the economic textbook fares very well. A classic is the experimental double oral auction. It very robustly leads to market clearing, as predicted by standard 
economic theory (Smith 1965; Smith et al. 1982). Yet in other institutional settings, standard economic theory is almost surely rejected in the lab. A well-known illustration is the ultimatum game (Güth et al. 1982). One of two randomly matched, anonymously interacting participants receives an endowment. Initially, the other player receives no money. The first player may propose any split of her endowment that she deems fit. This allocation is implemented if the second player accepts the proposal. Otherwise no player receives anything. Standard theory predicts that the proposer offers the smallest increment, and that the receiver accepts. Actually, most proposers offer the equal split. Offers below $20 \%$ of the endowment are rarely accepted (Oosterbeek et al. 2004).

Recently, criminologists have become interested in exploring the implications of standard findings from behavioral economics for understanding crime and the effect of criminal law (for a summary account Englerth 2010). They have for instance studied the effects of overconfidence (Dunning et al. 1990; Loughran et al. 2013), hyperbolic discounting (Laibson 1997; Loughran et al. 2012) and ambiguity aversion (Ellsberg 1961; Loughran et al. 2011) on the decision to commit crime. This ties into older work on a self-serving bias in the estimated effect of sanctions (Nagin and Pogarsky 2003), the perceived fairness of sanctions (Piquero et al. 2004), the motivating force of identity (Paternoster and Bushway 2008) and of morality (Paternoster and Simpson 1996; Brezina and Piquero 2007) and the ensuing disciplining effect of shaming (Rebellon et al. 2010), as well as work on impulsivity (Nagin and Pogarsky 2001; Nagin and Pogarsky 2003), on the perception of the risk of sanctions (Paternoster et al. 1983; Klepper and Nagin 1989; Nagin and Paternoster 1991) and on inter-individual differences (Nagin and Paternoster 1993; Nagin and Paternoster 1994; Piquero et al. 2011; Loughran et al. 2013).

One of the key issues in behavioral and experimental economics is social preferences. In the economic textbook, actors only care about their own payoff. The benefit need not be pecuniary. But the actor strives for more of this benefit for herself. If there is a cost, she chooses her activity level such that the additional gain from another unit of the pleasure exactly outweighs the additional disutility from the ensuing extra cost of effort. She completely ignores the beneficial or detrimental effects on other individuals. Experimental economists have doubted this implication of the standard model, and have developed a whole battery of tests to disprove it. Theoretical economists have translated their findings into formal models (see below section 2 for detail).

To the best of our knowledge, the potential of social preferences for the explanation of crime has been little explored. Tax evasion has been explained by the perceived prevalence of such behavior in the population, which could result from the fact that many taxpayers do not want to be the sucker (Cialdini 1989: 210-215; Kahan 2003: 80-85). The fact that women commit less crime has been explained by the fact that women show more empathy with victims (Broidy et al. 2003). In the theory section of this paper, we show that social preferences, as modeled by behavioral economists, could explain much more generally the decision not to engage in crime. Such preferences could also explain why sanctions deter crime even if the 
expected value of the sanction, i.e. the product of the probability of enforcement with the severity of punishment, is smaller than the benefit from crime.

It would be very difficult to test this explanation in the field. All the alternative explanations mentioned in the introductory paragraphs could also explain why individuals refrain from criminal activity. A host of social explanations could have the same effect, like socialization or the acquisition of non-criminal routines. All these explanations could also interact with social preferences. Even in the lab, many of these explanations could be relevant. Participants might for instance have moral compunctions against stealing from other, anonymous participants.

We therefore use an indirect approach. We work with two identifying assumptions. Behavioral economics, as all economics, takes preferences as given. They are revealed by choices. We need therefore not test individuals on criminal behavior if we want to explain, or predict, crime. If the theory of social preferences gets it right, we can test individuals on a situation unrelated to crime that forces them to reveal their social preferences. More importantly, we can design the experiment such that the only possible explanation for choices is social preferences. To that end, we use a standard tool from experimental economics, the dictator game (the game has been introduced by Kahneman et al. 1986: S290f.). Participants are randomly matched with one other participant. One participant is randomly assigned the active role. The other participant holds the passive role. The participant in the active role receives an endowment. The participant in the passive role remains unendowed. The active participant is free to share any fraction of her endowment with the passive participant. The active player's payoff is the endowment, minus what she sent to the passive player. The passive player's payoff is what she received from the active player. This game has been replicated more than 100 times. Many dictators give a sizeable fraction (Engel 2011). Results of this game give us a precise measure of an individual's willingness to give up some of her own income in the interest of increasing the income of another person who happens to have a lower income. The game has been interpreted as a measure of selfishness (see e.g. Bardsley 2008: 122), generosity (Kahneman, Knetsch et al. 1986: S286), sociality (Kahneman, Knetsch et al. 1986: S286 "social conscience") and altruism (e.g. Andreoni and Miller 2002).

If social preferences explain the decision not to engage in crime, individuals who give a lot in the dictator game should be less likely to commit crime than those who give little or nothing. Due to the dark field problem, identifying criminal behavior is genuinely difficult. We might have tested members of the general population on the dictator game, and have added a questionnaire about past criminal behavior. Yet we would then have faced the problems of selfreport data. In the spirit of experimental economics, we have preferred a measure for criminality that results from observed behavior. To that end, we have administered the dictator game to prison inmates. We thus work with the identifying assumption that prison inmates are more likely than members of the general population to actually have committed crime. We can of course not exclude false convictions, but deem their fraction to be small. This assumption is backed by institutional detail. We have run the experiment in Germany. In Germany, 
first offenders next to never go to jail. If the crime is not particularly severe, it takes a considerable criminal career before a convict ends up in jail. Juveniles are even less likely than adult convicts to do time in prison. We have run our test in a facility that only houses juveniles. It is therefore very unlikely that many of our participants are innocent. We can of course also not exclude that some members of the general public, which is our control group (see below), have also committed crime. They may just not have been caught, or they may even have been convicted, but only to pay a fine. Yet all we need for our purposes is a sufficiently pronounced difference in criminal activity. Given the strong selection effect inherent in the German system of criminal sanctions, this assumption seems well founded.

In experimental economics, the dictator game has been widely used to compare the social preferences of different populations, be that the members of a series of indigenous populations (Henrich and Boyd 2005; Henrich et al. 2006) or of developing countries in comparison with industrialized countries (Anderson et al. 2000; Ashraf et al. 2006), of different race (van der Merwe and Burns 2008; Fong and Luttmer 2009; Burns 2010), gender (Eckel and Grossman 1998; Andreoni and Vesterlund 2001; Houser and Schunk 2009), religion (Fershtman and Gneezy 2001; Ahmed 2008), cognitive ability (Chen et al. 2012), major (Carlsson et al. 2011) or profession (Jacobsen et al. 2011).

Despite being popular, population comparisons are not perfect. Population characteristics cannot be assigned randomly. There are two possible reactions to the resulting identification problem. The first strategy tries to match a treatment group with a control group that is as similar as possible. To the extent that potential moderating factors are observable, one may additionally use methods like propensity score matching to improve identification. In our case this would have meant running another dictator game with a control group of, say, male pupils attending a professional school from the same region, with similar social economic status, age and country of origin. We have preferred a second strategy. One of us has done a meta-study of all dictator games the results of which have been made publicly available until 2011. For a large fraction of these publications, even the original data could be reconstructed. The metastudy covers 41,433 observations (Engel 2011). We compare the prison data with this metadata. Our strategy seemed preferable for three reasons. The control group would only have helped us identify the treatment effect if we could have excluded that these pupils are criminals as well. For that we would have had to rely on self-report, which would have made this data questionable. We moreover have reason to believe that the socio-demographic factors prevalent in the prison population are not uncorrelated with crime. Had we neutralized these factors through matching, we would have compared a crime-prone control group with our treatment group of convicts. We would not have seen the association between social preferences and crime we are interested in. This is a much smaller concern with ordinary experimental participants who are taken from the general public. Finally, the meta-data are so rich that we also can compare the fraction prisoners give with the fraction given by normatively relevant comparison groups. 
We have a surprising finding. If we compare our prisoners with the meta-data from the general public, prisoners are not significantly more selfish. Actually descriptively, they are even more generous. We also do not find a significant difference if, instead, we compare dictator game giving of prisoners with giving among the members of close-knit groups. If we accept the identifying assumption that crime is more prevalent in the prison population than in the general public, a lack in social preferences cannot explain crime.

In our experiment, prisoners were deciding how much to give to another, anonymous inmate of the same prison. Anonymity was guaranteed and explained to participants. But we cannot completely rule out that a prisoner was afraid of later being forced by other prisoners to confess how much she had given, and that those who had given little were afraid of informal sanctions. Moreover prisoners might see other inmates as members of the same in-group toward which they feel solidarity. They might behave less selfishly toward other criminals than they would toward future victims of their crimes. The experimental literature suggests that this is not unlikely. Charitable giving to members of the same ethnic group has for instance been found to be higher than giving to members of another ethnic group (Chen and Li 2009). In a prisoner's dilemma, future officers in the Swiss Army who have been randomly assigned to a platoon for part of their training are much more likely to cooperate with another member of their random unit than with a participant from another random unit (Goette et al. 2010).

To rule out these alternative explanations, we ran a second experiment. On that occasion, we first replicated the original experiment with a fresh group of participants, and about three years later, with very similar results. More importantly, we sequentially had each prisoner take two decisions in the role of the dictator. In the first decision, the recipient was another prisoner from the same prison. In the second decision (which was only explained after prisoners had taken the first decision) they could decide how much of a new endowment to give to a well-known charity. On average prisoners gave considerably more to the charity than to other inmates of the same prison. This excludes the listed alternative explanations for giving to other prison inmates. Since prisoners do not give significantly less than non-prisoners in the dictator game, selfishness is clearly not the cause of these prisoners having committed their crimes.

The remainder of the paper is organized as follows: in the next section, we sketch the economics of social preferences and present a simple model for selfishness as a cause of crime. We then present the design and the results of our two experiments, and conclude with discussion.

\section{Selfishness as a Cause of Crime}

We will derive the hypothesis that selfishness might be a cause of crime from the most prominent economic model of social preferences (Fehr and Schmidt 1999). The majority of most experimental populations consist of what experimental economists call conditional cooperators. Such participants cooperate (behave in a socially desirable manner) as long as they see or 
expect most others to cooperate as well (Keser and van Winden 2000; Fischbacher et al. 2001; Frey and Meier 2004; Croson et al. 2005; Fischbacher and Gächter 2010). Most economic models of interdependent preferences (for overviews see Sobel 2005; Fehr and Schmidt 2006) want to capture this phenomenon. Models of reciprocity directly match conditional cooperation (Rabin 1993; Charness and Rabin 2002; Dufwenberg and Kirchsteiger 2004). Reciprocity models may further distinguish between other players' actions and their intentions (Falk and Fischbacher 2006). All of this may matter for the decision to commit crime. An employee destroys some of the employer's property because she thinks she has been treated unfairly. People evade taxes because they believe most others don't pay their taxes either. A woman abducts her child because the husband has committed adultery.

Yet for many other crimes, conditional cooperation is not a plausible explanation. Thieves do not steal from the department store because the firm running the store has misbehaved. Burglars do not break into someone's house because the owner has violated their legitimate expectations. A producer does not neglect environmental standards because those living in the neighborhood have proven not trustworthy. Yet even if reciprocity and intentions cannot matter, this does not exclude interdependent preferences. Would-be criminals can still take into account that their action imposes harm on victims. This is captured by models of altruism (Andreoni 1990; Cooper et al. 1996) and of inequity aversion. Altruism makes a very strong assumption. Altruists derive unconditional utility from seeing other people better off. Such individuals exist, but they are not frequent. Even if an individual is willing to give up some of her own payoff in the interest of increasing someone else's payoff, this willingness usually stops if the other individual is well off in the first place.

This consideration has led to the development of models of inequity aversion. Inequity averse individuals are only willing to give up some of their own payoff if the recipient is disfavored. A natural extension is aversion against being disfavored oneself. One model treats these two dimensions as symmetric (Bolton and Ockenfels 2000). Most readers see this as counterintuitive. It seems more natural that disadvantageous inequity carries more weight than advantageous inequity. This is the modeling choice of (Fehr and Schmidt 1999). ${ }^{1}$ The paper has been cited abundantly. ${ }^{2}$ We rely on this model.

In this model, an actor derives utility from three components: her payoff, disadvantageous and advantageous inequity. All three components are independent of each other. ${ }^{3}$ Inequity is expressed by the difference between this individual's payoff and the payoffs of those individuals with whom this individual compares herself. For simplicity, in the following we only consider the two-person case. ${ }^{4}$ Inequity only affects utility if there is a payoff difference. If the other individual has the same payoff, the second and the third terms of the utility function are zero.

1 There is a further difference between both models. While the utility function is linear in (Fehr and Schmidt 1999), it is quadratic in (Bolton and Ockenfels 2000). We will come back to this difference.

Google scholar lists 5301 citations.

The utility function is additively separable.

Extending the argument to the multi-person case is straightforward, (Fehr and Schmidt 1999). 
In comparison with the other individual, inequity can only be either advantageous or disadvantageous. Effectively, the utility function therefore never has more than two arguments. It depends on payoff comparison which of the three terms is zero and therefore immaterial. If there is inequity, in either direction, utility is reduced. Individuals are allowed to differ by the weight they attach to the two dimensions of inequity. ${ }^{5}$ We further assume that disadvantageous inequity carries more weight than advantageous inequity. ${ }^{6}$ Such an individual trades a smaller payoff to herself for a reduction of inequity. Given the function is linear in inequity, the individual either ignores inequity or she completely removes it. ${ }^{7}$

The following way, this model yields a prediction for the decision to commit crime. Assume that, initially, both individuals dispose of the same monetary endowment. Technically, no individual is prevented from appropriating some or all of the other individual's endowment. In the original version of our small model, there is no criminal law. Appropriation is free from risk. ${ }^{8}$ Obviously, this extremely simple model abstracts from many elements of social interaction that are sure to matter in reality. Taking money is free of charge. There is no alternative possibility for increasing one's payoff. Consequently crime has zero opportunity cost. Gains and losses from crime are completely certain. There are no social norms. Victims are prevented from protecting themselves and from taking revenge. The interaction is not repeated. Criminal activity does not lead to a loss in reputation. Both individuals are perfectly informed and even know the other individual's preferences. Both individuals have perfect cognitive abilities and know that the other has. None of these assumptions are particularly realistic. All of them together very rarely hold in the field. The purpose of our model, as of any model, is not to portray reality, but to make an effect visible. This model is meant to make the relationship between inequity aversion and crime visible.

Let us first assume that none of the two individuals is averse to inequity. ${ }^{9}$ In this society, both individuals deprive the other individual of her entire endowment. The individuals live in a perfect society of lions where property is completely disregarded. ${ }^{10}$ Let us now assume that this individual expects the other individual not to take money. Can it be a best response to

5 Formally, utility is given by (1) $u_{i}=\pi_{i}-\alpha_{i} \max \left(\pi_{j}-\pi_{i}, 0\right)-\beta_{i} \max \left(\pi_{i}-\pi_{j}, 0\right)$, where $\pi$ is payoff, actor $i$ is this individual, actor $j$ is her counterpart, and $\alpha$ and $\beta$ are weights attached to disadvantageous and advantageous inequity. The max-operator makes sure disutility from inequity is conditional on this form of inequity actually being present.

6 We thus assume $\alpha>\beta$.

7 Formally, choices are found by taking the first derivative with respect to the decision variable. This requires specifying the payoff functions of both individuals. We do so below for our application to crime.

8 Formally, payoff is given by (2) $\pi_{i}=e_{i}-t_{j}+t_{i}$. We assume complete symmetry, hence $e_{j}=e_{i}$, where $e$ stands for the endowment, and $t$ is how much either player takes from the other. Complete symmetry implies that, in equilibrium, individuals are indifferent between each individual keeping her endowment and each individual taking the other individual's endowment. This would be easy to change if we multiply $t_{i}$ by a factor $\gamma<1$. All results go through. We refrain from presenting this alternative model since this would make results considerably less transparent.

9 Formally, we first assume $\alpha_{i}=\alpha_{j}=\beta_{i}=\beta_{j}=0$.

10 Since we now have specified the payoff function, we find best responses by taking the first derivative of (2) with respect to the decision variable $t_{i}$. Since the function is linear, we have a corner solution. Since the best response is positive $(>0)$, individuals take the maximum amount, i.e. $e_{j}$. 
take no money herself? If this individual is selfish, i.e. if she suffers no disutility from inequity, the answer is no. For a selfish individual, this is the perfect world. She has nothing to fear for her own endowment, and gets a chance to exploit the other individual. She ends up with two endowments instead of one. Now we have assumed that preferences are common knowledge. Therefore, even if the first individual is socially minded herself, but knows the second individual to be selfish, she will not let the other create disadvantageous inequity by taking money. She will pre-empt this by herself taking money from the second individual. This would even follow if we had not assumed that disadvantageous inequity carries more weight than advantageous inequity. It suffices that the first individual dislikes disadvantageous inequity, which she prevents by taking moneyherself. The society of lions persists as long as one individual is selfish.

Yet what if both individuals are averse to advantageous inequity, and this is known? Now each individual may meaningfully decide what to do conditional on the other individual not taking any money. Provided her aversion against advantageous inequity is strong enough, it then is her best response not to take money as well. ${ }^{11}$ Actually it suffices if the individual dislikes outperforming the other individual slightly more than half as strongly as she desires a higher payoff for herself. The model thus can explain why there exist societies in which no stealing is observed even if property is unprotected and if there are no social or legal sanctions. We have prediction

$\mathbf{P}_{1}$ : If all individuals of a society dislike outperforming other individuals more than half as intensely as having a higher payoff for themselves, it is possible that property is respected, even absent social or legal sanctions.

Note, however, that this society is fragile. First, we only have shown that it is possible for such a society that nobody steals. ${ }^{12}$ Yet even if all individuals dislike advantageous inequity and this is known, it is only one possibility that truly nobody steals. It is an equilibrium. If one individual knows that the other individual does not steal, it is her best response not to steal either. Yet there are an unlimited number of equilibria. If this individual expects the other to take everything, she follows suit. Both individuals taking any fraction of the other individual's endowment is also an equilibrium. ${ }^{13}$

More importantly, we have assumed that preferences are perfectly known, and that both individuals strongly dislike outperforming the other. Effectively, we have only shown that the absence of crime is fragile even in a society of angels. What if, instead, this individual has to interact with an anonymous member of a group, and if a small fraction of this group will take

11 If we insert (2) into (1), take the first derivative with respect to $t_{i}$, and solve for $\beta_{i}$, we have $\beta_{i}=\frac{1}{2}$. At this point, the individual is indifferent between taking $e_{j}$ and refraining from doing so. She refrains from taking money whenever $\beta_{i}>\frac{1}{2}$.

12 In game theoretic parlance, we have shown existence, but not uniqueness.

13 This result is well known from the folk theorem (Aumann and Shapley 1994). 
money? ${ }^{14}$ Can it still be a best response not to take money herself? The answer is yes, but only if this individual dislikes outperforming the other individual even more strongly. ${ }^{15}$ Since now there is a positive risk that she will be exploited if she does not strike back pre-emptively, the relationship between her aversion against disadvantageous and against advantageous inequity also matters. Uncertainty about the other individual's type makes the socially desirable equilibrium even more fragile. This leads to prediction

$\mathbf{P}_{2}$ : If there is a risk that other individuals steal, it is still possible that individuals averse against advantageous inequity refrain from stealing themselves. But this requires stronger inequity aversion.

Many acts of crime go unpunished, for instance since the victim does not report to the police (see only MacDonald 2002). Those who regularly engage in criminal activity have a fair sense of the risk of being punished (Horney and Marshall 1992). Of course, the law could compensate for a small risk of punishment by higher severity (as suggested by Becker 1996: 144). But this would require a level of severity that most legal orders find undesirable. In such legal orders, perfectly selfish individuals are not deterred. Yet punishment is not pointless provided a sufficient fraction of the society is averse against advantageous inequity. ${ }^{16}$ If they face a risk of punishment in case they pre-empt exploitation by striking back, inequity averse individuals are more likely to refrain from stealing. Punishment helps maintain an equilibrium where inequity averse individuals face a small risk of being the victims of theft. Punishment stops the vicious cycle even if individuals are not strongly averse to advantageous inequity.

Figure 1 illustrates the result for a situation where the individual is twice as averse to disadvantageous as she is to advantageous inequity, and where she knows or expects her counterpart to be selfish with probability $10 \%$. The left panel shows for which combinations of the expected value of punishment and aversion to advantageous inequity the individual refrains

14 In that event, (1) is replaced by (3) $u_{i}=\pi_{i}-p \alpha_{i}\left(\pi_{j}-\pi_{i}\right)-(1-p) \beta_{i}\left(\pi_{i}-\pi_{j}\right)$, where $p$ is the known or estimated probability that $t_{j}=e_{i}$. Within the framework of the model, $p>0$ may result from one of two reasons. Either $E_{i}\left(\beta_{j}\right)<\frac{1}{2}$ : this individual expects the other individual to be insufficiently averse to advantageous inequity. Or $E_{i}\left(E_{j}\left(p_{i}\right)\right)>0$ : this individual expects the other individual to expect the first individual to take with positive probability. This requires $E_{i}\left(E_{j}\left(\beta_{i}\right)\right)<\beta_{\text {crit }}$, with critical $\beta$ as defined in the following footnote: this individual expects the other individual to expect this individual to be not so strongly averse to advantageous inequity that she even tolerates a given risk of stealing. In the resulting game, both individuals not stealing constitutes a Bayes Nash equilibrium provided both individuals hold prior beliefs such that the other individual steals with a probability smaller than $E\left(p_{j}\right)<\frac{2 \beta_{i}-1}{2 \beta_{i}+\alpha_{i}}$.

15 Proceeding as before, we calculate that this individual is indifferent between taking money and abstaining from doing so if $\beta=\frac{1+2 p \alpha}{2-2 p}$. If we let $\alpha=2 \beta, p=\frac{1}{10}$, the critical $\beta$ raises to $\frac{5}{7}$.

16 To account for the risk of punishment, (2) is replaced by (4) $\pi_{i}=e_{i}-t_{j}+t_{i}-q \sigma t_{i}$ where $q$ is the probability of punishment and $\sigma$ is its severity. Severity is assumed to be proportional to the amount taken. Inserting (4) into (3), taking the first derivative with respect to $t_{i}$, and solving, we calculate $\beta=$ $\frac{1-q \sigma+p \alpha(2-q \sigma)}{(1-p)(2-q \sigma)}$. This is less than the critical $\beta$ if there is a risk of exploitation, but no punishment. The difference consists of $\Delta \beta=\frac{q \sigma}{(1-p)(2-q \sigma)}$. 
from stealing. This is the case whenever, in that figure, the blue surface is below the green surface. As one sees, both parameters are substitutes. The higher the aversion against advantageous inequity, the lesser punishment is needed to deter such an individual from stealing. The right panel compares choices of individuals who are averse against advantageous inequity with and without punishment. The blue surface is always below the red surface. However small its expected value, the threat of punishment always reduces the risk that an inequity averse individual steals. This distance increases both in the expected value of the sanction and in the aversion against advantageous inequity.

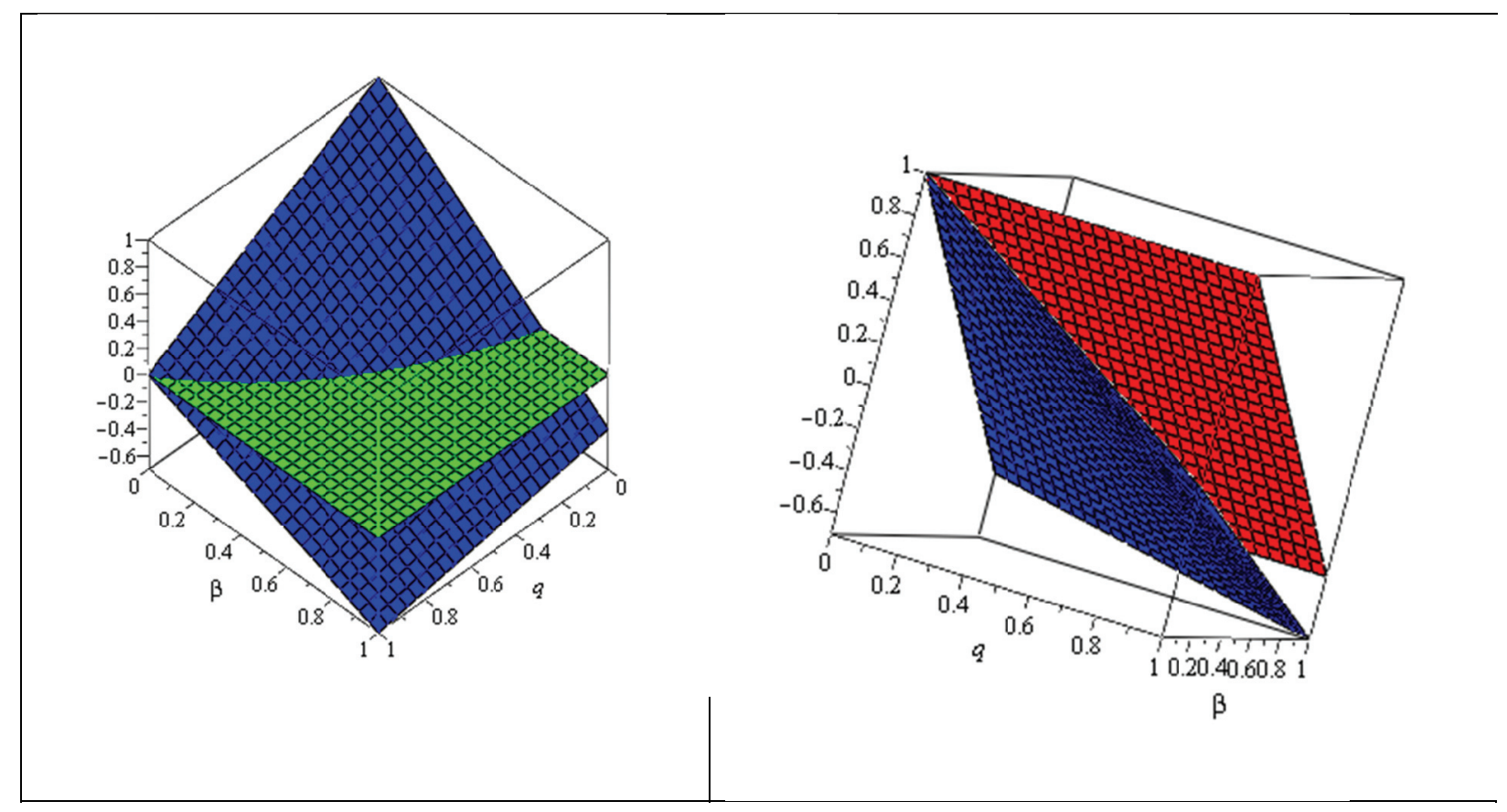

Figure 1

Effect of Punishment on Inequity Averse Individuals

Blue Surface: best response conditional on $\alpha=2 \beta, p=\frac{1}{10}, \sigma=1$ and various values of $q$ and $\beta$ Green Surface: best response $=0$; for values of $q$ and $\beta$ such that the blue surface is below the green surface, the individual does not steal since here best response is negative Red Surface: best response conditional on $\alpha=2 \beta, p=\frac{1}{10}$, absent punishment

This leads to our final prediction

$\mathbf{P}_{3}$ : Individuals who are averse against advantageous inequity are deterred by punishment even if its expected value is smaller than the expected benefit from crime. 


\section{Study 1}

\section{a) Empirical Strategy}

In principle, our theory invites a direct test in the lab. We could translate the payoff functions on which our theory rests into the design of an experiment. If we generate a reliable measure of the aversion of participants against advantageous inequity, we could use this measure to explain choices in the stealing game. In this game, we could match participants with partners that have a defined degree of aversion against advantageous inequity. In a further treatment, we could introduce exogenous punishment with defined expected value.

Yet with this strategy, we would face an identification problem. We would only see correlation between inequity aversion and stealing, but we could not say whether the degree of inequity aversion is actually the cause of crime. We could not exclude that inequity averse participants refrain from stealing for reasons that are unrelated to inequity aversion. There are many plausible candidates, like risk aversion, moral inhibition, or a construction of the situation that rules out stealing from the action space. We could also not exclude that any of these alternative explanations interact with inequity aversion.

To overcome this problem, we do not induce crime in the lab, but measure crime exogenously. Specifically we rely on the assumption that prison inmates are more likely to actually be criminals than members of the general public. This of course implies that we measure inequity aversion at a point in time after the documented crime. Yet for our theory this does not create a problem. The theory treats inequity aversion as a personality variable that is stable over time and, critically, not influenced by having committed crime. We thus translate the predictions of our theory into the following testable hypothesis:

$\mathbf{H}_{1}$ : Prison inmates are less averse against advantageous inequity than members of the general public.

This empirical strategy has the further advantage of higher external validity. Prisoner status as our proxy for crime is associated with real crime, not only with analogous behavior in the lab. For the reasons explained in the introduction we prefer comparing the degree of aversion against advantageous inequity that we measure in prisoners with meta-data from all pertinent experiments that have been conducted until 2011, rather than repeating the experiment with a control group that is matched on demographic characteristics.

Note that our claim is limited to advantageous inequity. We operationalize selfishness as a lack of aversion against advantageous inequity, and investigate whether this explains crime. It may well be that (some) prison inmates felt justified to commit crime since they regard themselves as disadvantaged. They may have constructed crime as a means of redressing the distributional balance. We do thus not mean to exclude inequity aversion as a cause of crime. All we are interested in is selfishness. We want to learn whether committing crime is caused by a lack of aversion against being ahead of others. 


\section{b) Design}

Our measure for aversion against advantageous inequity is a game that is so simple that alternative explanations can be ruled out. In the dictator game, two players are randomly and anonymously matched. One player is randomly assigned the active role. This player receives an endowment of $5 €$ (at the exchange rate of the first experimental day: $7.34 \$$ ). The other player has no endowment. The active player is free to keep the endowment or to send any fraction to the passive player. To reduce complexity, the action space is constrained to multiples of 50 Cents, or to integers of experimental currency units, worth 50 Cents each. In the interest of getting a data point from each participant, we use the strategy method (Selten 1967). Each participant decides in the active role, but this decision is only executed for half of the participants. Roles are randomly assigned by the computer, after each participant has committed to a decision in the active role. This procedure is explained to participants. The experiment was computerized, using the software zTree (Fischbacher 2007).

In this game, a selfish player keeps her entire endowment. ${ }^{17}$ By contrast, a player who is averse against advantageous inequity sends half of the pie if she dislikes outperforming the passive player more than half as strongly as a higher payoff for herself. ${ }^{18}$ Consequently we support $\mathbf{H}_{\mathbf{1}}$ if prisoners are significantly more likely to keep their endowment than members of the general public.

In the experimental literature on dictator games, following (Hoffman et al. 1994; Hoffman et al. 1996) experimenters often guarantee dictator-experimenter anonymity through a "double blind" protocol. In keeping with this tradition, we assigned each participant an identification number. The prison administration matched identification numbers with demographic information on the respective participant, while we never learned his name. Participants were aware of this safeguard.

\section{c) Sample}

On three subsequent days in October 2009, 58 male inmates of the Adelsheim prison participated in the experiment. Adelsheim prison was built in 1974 to house juvenile delinquents. In 2008, the prison had 765 inmates. Those who left the prison in 2008 had on average served 11 months. $24 \%$ had served less than 6 months. Less than $4 \%$ had served more than 24 months. In our sample, mean age was 19.64 years, range [18,24]. They on average served a sentence of 27.82 months, range [6,84]. They on average had already served 9.26 months at the time of the experiment, range $[1,46] .34$ were convicted for violent crime, 44 for property crime.

17 Such a player has payoff (5) $\pi_{i}=e_{i}-g_{i}$, where $g_{i} \leq e_{i}$ stands for the fraction she sends to the passive player. The first derivative with respect to the decision variable $g_{i}$ is -1 . We have a corner solution. A selfish player sends nothing.

18 Such a player has utility as in (1). Inserting (5), taking the first derivative with respect to $g_{i}$, and solving for $\beta_{i}$, we find critical $\beta_{i}=\frac{1}{2}$. Note the strict parallel to the stealing game from the theory section. 
For our prisoners, $5 €$ is a sizeable amount of money. On average, per month, they approximately dispose of $180 €$. Average earnings of all participants were $2.50 €$ by design. Prisoners have a prison account, and can use money from that account to buy goods in the prison shop. That way, real money is a meaningful currency for them.

\section{d) Results}

We have a surprising finding, left panel of Figure 2. Only 20 of our 58 participants, or 34.48 $\%$ of them, keep the entire amount. The remaining 38, i.e. $65.52 \%$, give a positive amount. 12 of them, or $20.69 \%$ of them, give even more than half of the pie. Even in the perfectly secure lab situation, almost two thirds of our prison participants behave in a way that cannot be explained in terms of selfishness.

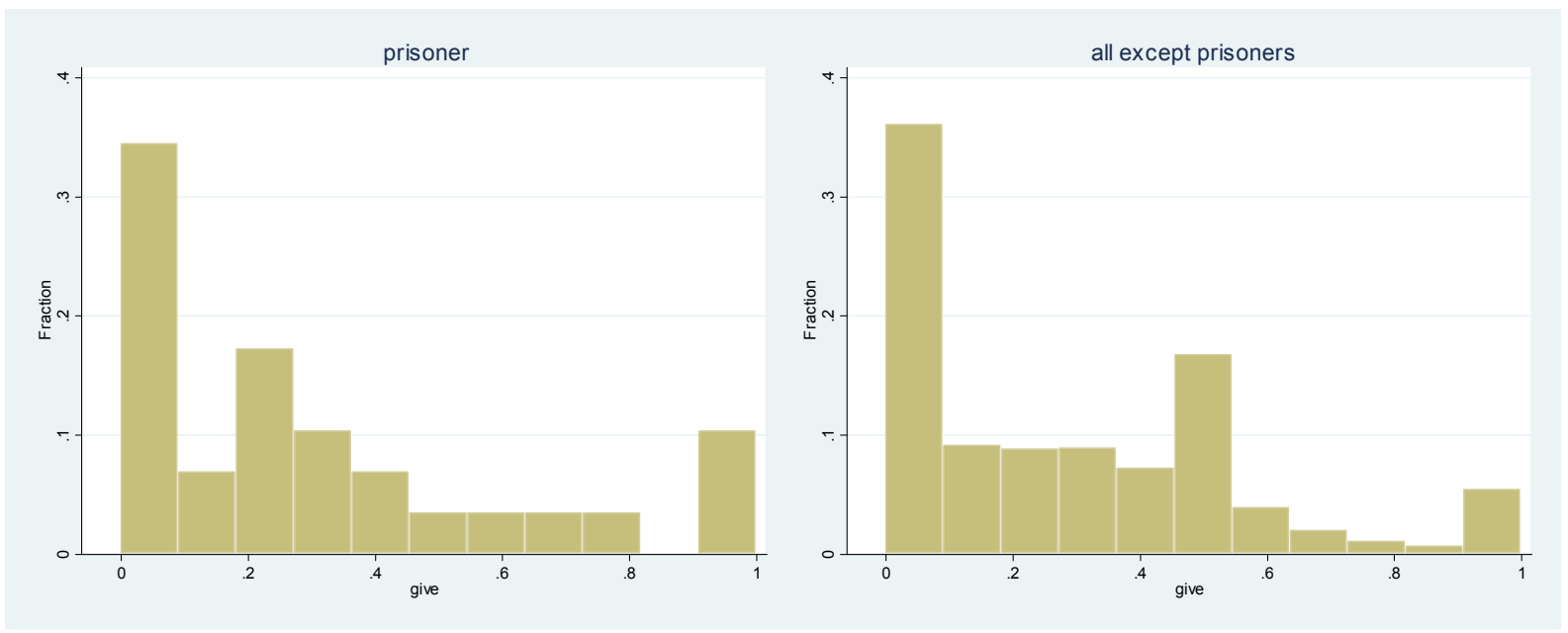

Figure 2

Comparison with Ordinary Experimental Participants

The comparison with the data from the meta-study of all dictator game experiments that have previously been made available ${ }^{19}$ is even more surprising, Figure 2. On average all participants of all 616 previously reported treatments contribute $28.35 \%$ of their endowment. ${ }^{20}$ Our prison subjects on average contribute $29.31 \% .36 .11 \%$ of the members of the general public keep their entire endowment, while only $34.48 \%$ of the prisoners do.

Our model predicts that individuals who are not or not sufficiently averse to advantageous inequity do not give anything to the recipient when having the role of the dictator. The most

19 The meta-study covers 129 papers publishing dictator games, including working papers, between the beginning of the literature in 1986 and the end of 2009. From these 616 treatments, 445 do not only offer means, but standard deviations, so that meta-regression can be performed. For 328 treatments, using reported distributions of results, the original data can be reconstructed, generating a dataset of 20,817 observations (for sample composition and methodology see Engel 2011).

20 If we run a meta-regression on those 445 treatments with information on standard deviations, we get almost the same result, $28.3 \%$. The mean of the reconstructed 20,813 datapoints is 27.24 . For technical detail of these alternative measures see (Engel 2011). 
straightforward test of this prediction is a binary variable that is 1 if the dictator gives nothing, and 0 otherwise. If selfishness is the cause of crime, prisoners should be more likely to give nothing in the dictator game. Model 1 of Table 1 shows that this is not the case. The effect of being part of the prison population is far from significant. We offer two additional statistical tests. ${ }^{21}$ Model 2 treats the fraction of the pie as a continuous variable and estimates a linear model. Model 3 makes the additional assumption that dictators who give nothing would even have wanted to take money from the recipient, had the design of the experiment not made this impossible. This way of capturing the censored nature of the data is empirically well founded. When given the opportunity, dictators do indeed take money (List 2007; Bardsley 2008). In neither model we find a significant difference between prisoners and members of the general public.

\begin{tabular}{|l|l|l|l|}
\hline & Logit0 & OLS & Tobit0 \\
\hline Prison & -.071 & .021 & .028 \\
& $(.493)$ & $(.217)$ & $(.251)$ \\
\hline cons & -.571 & .272 & .173 \\
& $(<.001)$ & $(<.001)$ & $(<.001)$ \\
\hline $\mathrm{N}$ & 20871 & 20871 & 20871 \\
\hline
\end{tabular}

Table 1

Comparison with General Public: Statistical Tests

all models cluster standard errors for studies

Logit0: $d v$ is a dummy that is 1 if the participant has given nothing

OLS: $d v$ is fraction of pie, normalized on the interval $[0,1]$

Tobit0: $d v$ as in OLS, lower level 0

$\mathrm{p}$-values in parenthesis

This gives us

Result 1: Prisoners do not give less than members of the general public in the dictator game.

One might object that our prison participants knew they were interacting with an anonymous inmate of the same prison. In the standard dictator experiment, student subjects know they are matched with another anonymous member of the same subject pool. Subject pool size is rarely reported. The subject pool of our own lab in Bonn with more than 5000 registered partici-

21 The model of inequity aversion by (Fehr and Schmidt 1999), on which we build our theory, is linear. It predicts that participants give nothing in the dictator game if they suffer from advantageous inequity disutility that is smaller than half the utility from additional income for themselves. The model predicts that, otherwise, they equalize payoffs. Obviously, participants use a more complicated utility function that allows for intermediate give rates and even giving above the equal split. This is acknowledged in (Fehr and Schmidt 1999: 847-850), but they do not offer a formal alternative. The following utility function would be able to represent this behavior (6) $u_{i}=e_{i}-g_{i}-\tilde{\beta}\left(\frac{e_{i}-g_{i}}{g_{i}}-1\right)$. In this utility function, my utility is the smaller the more my income differs from the income of my partner. Only that now the relationship between incomes is expressed by a fraction, not by a difference. This yields an interior solution. We refrain from offering a complete model based on this alternative definition of the utility function since the nonlinearity makes the model very intransparent. 
pants is probably rather on the large side. Nonetheless one might argue that our prison participants had the impression of interacting with a member of a considerably smaller group, and that this group, all being walled in, was tied together more densely than students of the same university. It might therefore seem more appropriate to compare our sample with dictators who interact with other members of a more tightly defined group. Other experimenters have tested students who attend a school preparing them for entering the Indian Muslim clergy (Ahmed 2008); members of small Honduran villages directly after they had been hit by Hurricane Mitch (Carter and Castillo 2005); or they used a pretest to classify social distance, and matched participants accordingly (Leider et al. 2009; Aguiar et al. 2010). Of course, in these populations social proximity does not have the same origin as among inmates of the same prison. Yet the clergy example shares the intensity of social interaction, and the practical impossibility of leaving the group. The hurricane example shares the fact that individuals have not freely joined the group.

Figure 3 shows that these results do indeed look similar. Again mean contributions are very close. Non-prisoners on average contribute $29.12 \%$ of their endowment, while prisoners contribute $29.31 \%$. Statistically, there is still no significant difference, Table 2.
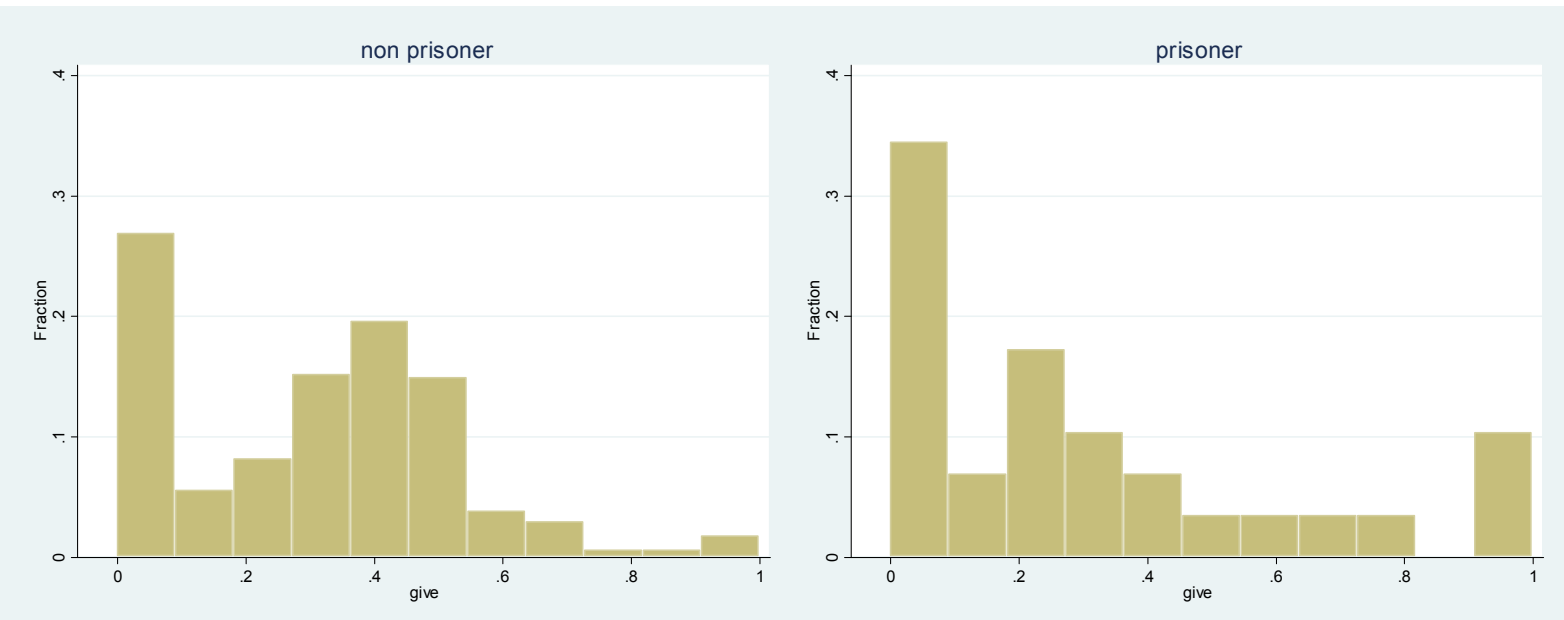

Figure 3

Comparison with Close Knit Groups

\begin{tabular}{|l|l|l|l|}
\hline & Logit0 & OLS & Tobit0 \\
\hline Prison & .358 & .002 & -.014 \\
& $(.210)$ & $(.940)$ & $(.686)$ \\
\hline cons & -.999 & .291 & .239 \\
& $(<.001)$ & $(<.001)$ & $(<.001)$ \\
\hline $\mathrm{N}$ & 400 & 400 & 400 \\
\hline
\end{tabular}

Table 2

Comparison with Close Knit Groups: Statistical Tests

all models cluster standard errors for studies

Logit0: $d v$ is a dummy that is 1 if the participant has given nothing

OLS: $d v$ is fraction of pie, normalized on the interval $[0,1]$

Tobit0: $d v$ as in OLS, lower level 0 
We reject $\mathbf{H}_{\mathbf{1}}$ and conclude

Result 2: In the dictator game prisoners do not give less than members of close knit groups.

\section{Study 2}

\section{a) Empirical Strategy}

The results from our first study might be criticized from two angles. We had a relatively small sample. We might therefore not have found a significant difference for reasons that are specific to this sample, rather than general for prisoners. Moreover, while the comparison with other close-knit groups suggests that social cohesion is not the explanation, we cannot strictly rule out alternative explanations that are specific for donations from one prisoner to another, like fear for being forced to confess choices after the experiment.

To rule out such explanations, we have rerun the original experiment and have now also tested prisoners on a second dictator game. In this second game, recipients are not other prisoners but a well-known and well regarded charity, Brot für die Welt. If social cohesion indeed is the explanation, prisoners should give less to the charity than to other inmates of the same prison, if anything. If, however, prisoners' selfishness does not differ from selfishness in the general population, they should give more to the charity. For charities and especially needy recipients have repeatedly been shown to receive a higher fraction of the pie than other, unendowed participants (Eckel and Grossman 1996; Small and Loewenstein 2003; Branas-Garza 2006; Fong 2007). In a meta-regression that only tests for the effect of the recipient being particularly deserving, the mean fraction given increases from $26.1 \%$ to $37.6 \%$ of the pie. If one controls for all explanatory factors that have been reported, the fact that the recipient is deserving increases the fraction given by $8.6 \%$. Both ways of estimating the effect lead to a highly significant result (Engel 2011). We thus test

$\mathbf{H}_{2}$ : In a dictator game, prisoners give less to a charity than to another anonymous inmate of the same prison.

This approach has two further advantages. We are replicating the original study with a fresh group of participants. And we now have a true treatment effect, not only the possibility to compare across populations. Within subjects, we now have two decisions from each prisoner. When deciding how much to give to another anonymous prisoner, participants did not know that a second dictator game was to follow. ${ }^{22}$

22 We did not counterbalance order since, for our research question, the critical question is whether prisoners give less if the pull of social cohesion is removed. 


\section{b) Design}

For the first test we use the same design as in Study 1. After participants have indicated their choice in case they receive the active role, the computer randomly assigns roles and gives the dictator and the recipient feedback. Participants know the experiment has a further part, but they do not know what this part is about. They then are informed that the structure of the game remains the same. They receive the same endowment of $5 €$. Now all participants with certainty decide in the active role. The recipient is the charity Brot für die Welt. Participants are informed that the experimenters will send to this charity any amount they decide to give. They also learn that they will receive a transcript of the bank transaction so that they can verify that the money has actually been used for its designed purpose.

\section{c) Sample}

On two subsequent days in October 2012, 62 male inmates of the Adelsheim prison participated in the experiment. In the new sample, mean age was 19.81 years, range [17,23]. They on average serve a sentence of 33.10 months, range [6,78]. They on average had already served 9.47 months at the time of the experiment, range $[1,46]$. 40 were convicted for violent crime, 26 for property crime. No participant of the second experiment participated in the first experiment. $^{23}$

\section{d) Results}

As Figure 4 shows, we replicate the pattern from the first experiment. 38 of our 62 participants give a positive amount to the other, anonymous inmate of the same prison. 16 give half of the endowment or more.

23 The prison administration identifies prisoners by a number. Prisoners gave us this number. From the prison administration we received demographic information. At no point did we know which real name stands for which identification number. Prisoners knew that we did not learn their names. Through comparing identification numbers across experiments we can exclude that a prisoner has participated in both experiments. Actually no more than two participants of the second experiment were already doing time in the prison in 2009, when we conducted the first experiment. 


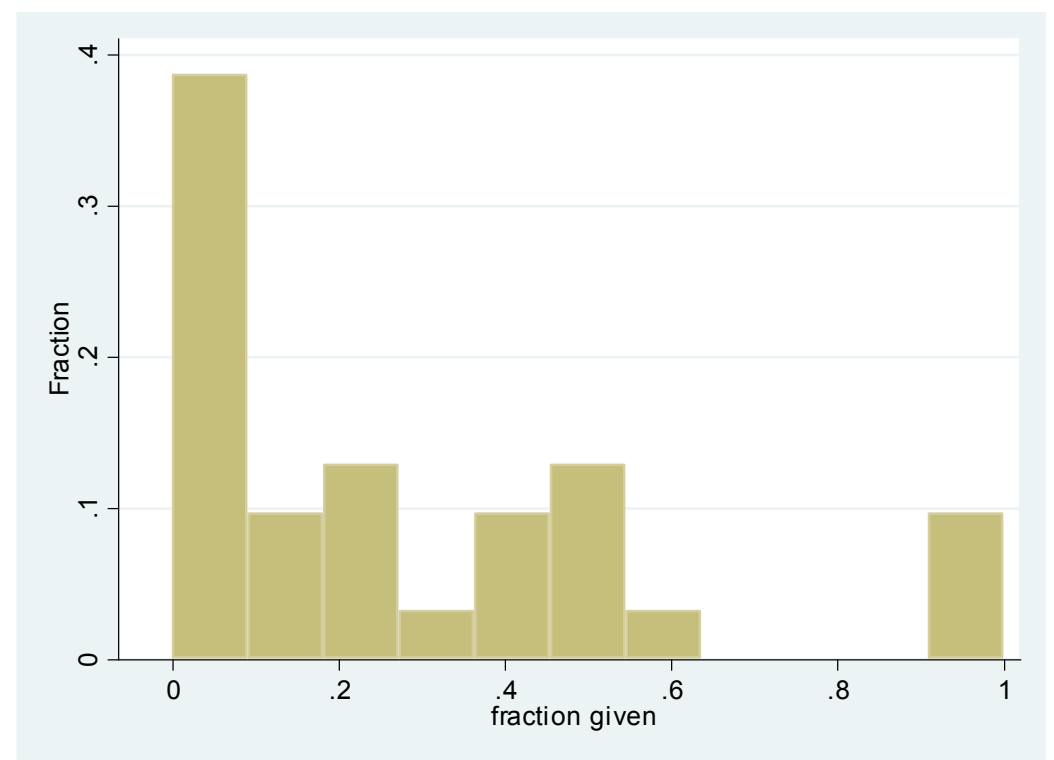

Figure 4

Study 2: Prisoner to Prisoner Giving

The more important finding is in Figure 5. While there are indeed a few prisoners who give a substantial amount to other prisoners, but little or nothing to the charity, the predominant pattern is the opposite one. Prisoners give little or nothing to another anonymous prisoner, but they give a substantial amount, if not everything, to the charity. The regression in Table 3 shows that the effect is not spurious.

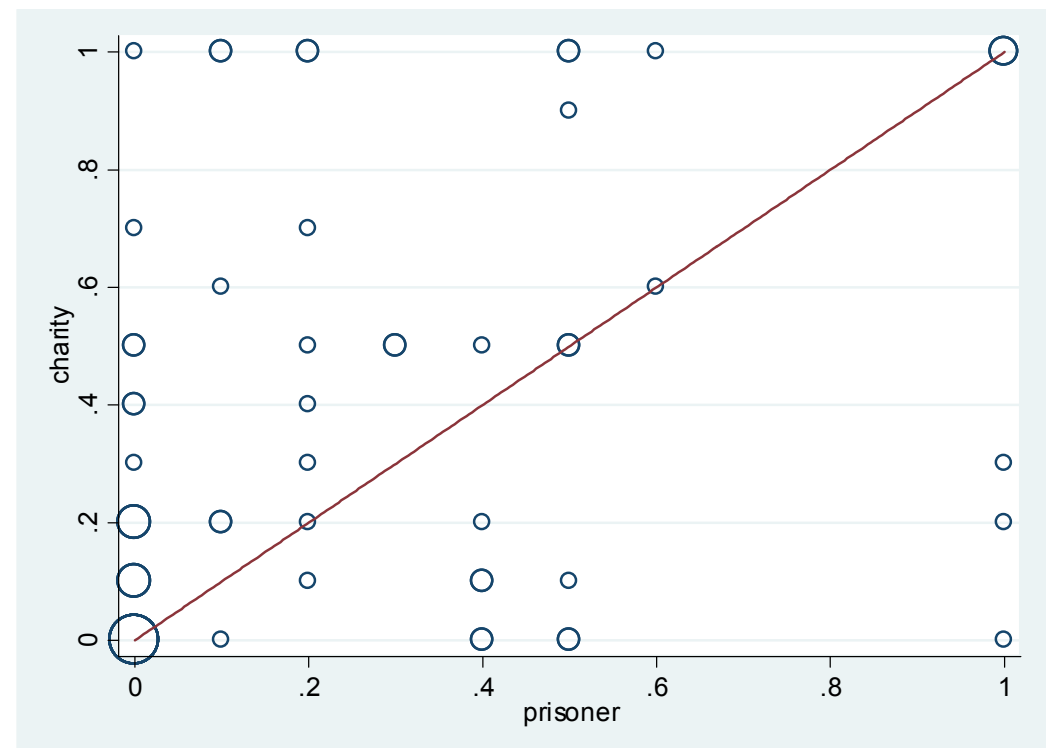

Figure 5

Giving to Another Prisoners vs. to a Charity

bubble size stands for the frequency of a combination of choices

bubbles are above the line if a participant has given more to the charity than to another prisoner 


\begin{tabular}{|l|l|}
\hline charity & $.110^{\star}$ \\
\hline cons & $.265^{\star * *}$ \\
\hline $\mathrm{N}$ & 124 \\
\hline p model & .0308 \\
\hline
\end{tabular}

Table 3

Giving to Another Prisoners vs. to a Charity: Statistical Test

linear fixed effects regression

This rejects $\mathbf{H}_{2}$, and gives us

Result 3: In a dictator game, prisoners give more to a charity than to an anonymous other inmate of the same prison.

\section{Discussion}

For a rational choice theorist, the difficult thing to explain is not the presence but the absence of crime. A rational choice theorist has two options: either the benefit from crime is too low, or the cost of crime is too high. For each explanation there are plausible applications. Most people don't have the desire to kill others. Many people dread time in prison more than they desire possessing goods they have no money to buy. Yet rational actors multiply the loss in utility from the enforcement of punishment by the probability that this is actually going to happen. For many instances of petty crime, the probability of enforcement is notoriously small. There could be additional social sanctions, like a loss in reputation or outright revenge. Gains from crime could be smaller than gains from legal uses of scarce human capital. Nonetheless it seems plausible that for many more would-be criminals the balance between benefit and cost is positive, and they still do not commit crime.

In this paper we capitalize on one prominent theory from behavioral economics to offer an additional explanation for the absence of crime. Would-be criminals might hold interdependent preferences. Specifically they might be averse to advantageous inequity. The utility of such an individual is reduced if she outperforms others. In a formal model we show three things: (1) If all individuals of a society are sufficiently averse to advantageous inequity, nobody committing crime (taking someone else's goods) is an equilibrium. (2) Even if individuals expect others to commit crime with positive probability, and if they are also averse to being outperformed themselves, not committing crime can be a best response. Such a society is thus robust to heterogeneity of preferences. Yet this robustness requires an even higher aversion to advantageous inequity. (3) The degree of aversion to advantageous inequity required to stabilize a heterogeneous population is reduced by punishment, even if the expected value of the sanction is smaller than the benefit from crime. Inequity aversion thus offers an explanation for the instrumentality of an incomplete threat with punishment. 
To test this theory, we use experimental data. We rely on two identifying assumptions: prisoners are more likely to be criminals than members of the general public; aversion against advantageous inequity is a personality trait. We therefore test prisoners on a game where inequity aversion is the only possible explanation. We have two surprising findings. Prisoners are not less averse to advantageous inequity than members of the general public, and not even than members of close-knit social groups. Prisoners on average give more to a charity than they give to another anonymous inmate of the same prison. Given these findings and our identifying assumptions, we reject the theory. Aversion against advantageous inequity alone is not sufficient to explain the absence of crime even if sanctions are imperfect.

The difference between the giving to other prisoners and to a charity might have several reasons. Criminals might distinguish between targets. They might feel no urge to spare anonymous co-prisoners, while they are not only reticent to impose harm on the poorest of the poor; they might even feel they should actively do something to improve their dire fate. Prisoners might also interpret giving to the charity as an act of compunction and penance for their own previous crime. They might even see this game as an opportunity to show to us experimenters that they hold socially desirable preferences. Since it adds a frame, the second dictator game is less clean than the first. We cannot exclude all explanations that might compete with aversion against advantageous inequity. Yet this is not a limitation of our study. We only need the second experiment to exclude social proximity as the cause of giving in the first experiment. The first experiment is unframed, and therefore not open to the alternative interpretations.

There are two possible reasons why we do not find experimental support for our theory, in neither experiment. The first possibility concerns our estimation strategy. The identifying assumptions might be too strong. The first assumption is certainly not always valid. There are wrongful convictions and, probably even more importantly, there is a dark field. Still it seems highly unlikely that members of the general public commit more crime than prisoners. The fact that we have run the experiment in a German prison for the adolescent provides additional support. In Germany, most crime is sanctioned with a fine, not with prison. Young criminals are kept out of prison for a very long time. Those who end up in prison must show a protracted criminal career.

The second identifying assumption may be more critical. Outside the crime context, experimental economists have tried to test the assumption that inequity aversion is a personality trait, with rather mixed results (Blanco et al. 2011). Others have had more success and claim that it is critical to control for moderating variables, and for beliefs in particular (Engel and Zhurakhovska 2012). We cannot decide the issue here, and must leave it for future work to find moderating variables that might make the main effect of inequity aversion visible in the crime context.

The second possible reason why we cannot support our theory is that the theory might be too simple. Behavioral economists use the terms interdependent preferences and social prefer- 
ences almost exchangeably. This might not fit the behavior of many individuals who do not commit crime although deterrence is incomplete or totally absent. Such individuals might be reticent to disregard others' property, honor, health or life, even if they are not prepared to share their own property with them. Inequity aversion only looks at relative payoffs. By contrast, individuals might sense a profound divide between committing intrusion and omitting help. Thus far, this distinction has attracted much less attention from behavioral researchers (a recent exception is Zamir and Ritov 2012). Yet it might be important for understanding the absence of crime and the effect of imperfect sanctions. Yet Zamir and Ritov find that participants are more reticent to inflict harm on bystanders if harm results from their action, rather than their inaction. We do, however, find that criminals are not less willing to actively help bystanders. If a lack in aversion to advantageous inequity was a cause of crime, a fortiori should they be less willing to actively share some of their property with the needy. Eventually investigating this explanation must be left to future work. Until then, at the least we can say: it could not be shown that selfishness is a cause of crime. 


\section{References}

Aguiar, Fernando, Pablo Branas-Garza and Maria Paz Espinosa (2010). "Personal Identity. A Theoretical and Experimental Analysis." Journal of Economic Methodology 17: $261-275$.

Ahmed, Ali M. (2008). Are Religious People More Prosocial? A Quasi-Experimental Study with Madrasah Pupils in a Rural Community in India http://ideas.repec.org/p/hhs/gunwpe/0330.html.

Anderson, Lisa R., Yana V. Rodgeres and Roger R. Rodriguez (2000). "Cultural Differences in Attitudes Toward Bargaining." Economics Letters 69: 45-54.

Andreoni, James (1990). "Impure Altruism and Donations to Public Goods. A Theory of Warm-glow Giving." Economic Journal 100: 464-477.

AndReOni, JAmes and John Miller (2002). "Giving According to GARP. An Experimental Test of the Consistency of Preferences for Altruism." Econometrica 70: 737-753.

AndReOni, JAmeS and Lise Vesterlund (2001). "Which is the Fair Sex? Gender Differences in Altruism." Quarterly Journal of Economics 116: 293-312.

Ashraf, Nava, Iris Bohnet and Nikita Piankov (2006). "Decomposing Trust and Trustworthiness." Experimental Economics 9: 193-208.

Aumann, Robert J. and Lloyd S. Shapley (1994). Long Term Competition - A Game Theoretic Analysis. Collected Papers I. R. J. Aumann. Cambridge, MIT Press: 395-409.

Bachman, Ronet, RAymond PATERnOSter and SALly WARD (1992). "The Rationality of Sexual Offending. Testing a Deterrence/Rational Choice Conception of Sexual Assault." Law and Society Review 26: 343-372.

Bardsley, Nicholas (2008). "Dictator Game Giving. Altruism or Artefact?" Experimental Economics 11: 122-133.

BeCKer, GARY S. (1996). Accounting for Tastes, Harvard University Press.

Becker, Gary Stanley (1968). "Crime and Punishment. An Economic Approach." Journal of Political Economy 76: 169-217.

Becker, Gary Stanley (1976). The Economic Approach to Human Behavior. Chicago, University of Chicago Press.

Blanco, Mariana, Dirk Engelmann and Hans-Theo Normann (2011). "A WithinSubject Analysis of Other-Regarding Preferences." Games and Economic Behavior 72: 321-338. 
Bolton, Gary E. and Axel Ockenfels (2000). "ERC: A Theory of Equity, Reciprocity and Competition." American Economic Review 90: 166-193.

Branas-Garza, Pablo (2006). "Poverty in Dictator Games. Awakening Solidarity." Journal of Economic Behavior \& Organization 60: 306-320.

Brezina, Timothy and Alex R. Piquero (2007). "Moral Beliefs, Isolation from Peers, and Abstention from Delinquency." Deviant Behavior 28(5): 433-465.

Broidy, lisa, Elizabeth Cauffman, Dorothy l. Espelage, Paul Mazerolle and Alex R. Piquero (2003). "Sex Differences in Empathy and Its Relation to Juvenile Offending." Violence and Victims 18(5): 503-516.

Burns, Justine (2010). Race and Social Interactions in Post-Apartheid South Africa. Discrimination in an Unequal World. M. A. Centeno and K. S. Newman. Oxford, Oxford University Press: 88-108.

Carlsson, Frederik, Mitesh Kataria, Elina Lampi and M.Vittoria Levati (2011). Doing Good with Other People's Money. A Charitable Giving Experiment with Students in Environmental Sciences and Economics http://gupea.ub.gu.se/dspace/bitstream/2077/24287/1/gupea_2077_24287_1.pdf.

Carter, Michael R. and Marco Castillo (2005). Morals, Markets and Mutual Insurance. Using Economic Experiments to Study Recovery from Hurricane Mitch. The Social Economics of Poverty. C. B. Barrett. New York, Routledge: 268-287.

Charness, Gary and Matthew RABIN (2002). "Understanding Social Preferences with Simple Tests." Quarterly Journal of Economics 117: 817-869.

Chen, Chia-Ching, I-Ming Chiu, John Smith and Tetsuij Yamada (2012). Too Smart to Be Selfish? Measures of Cognitive Ability, Social Preferences, and Consistency http://mpra.ub.uni-muenchen.de/41078/.

Chen, YAN and Sherry XIN Li (2009). "Group Identity and Social Preferences." American Economic Review 99: 431-457.

Cialdini, Robert B. (1989). Social Motivations to Comply. Norms, Values and Principles. Taxpayer Compliance. J. A. Roth and J. Scholz. Pennsylania, University of Pennsylvania Press. 2: 200-227.

Cooper, Russell, Douglas V. DeJong, Robert Forsythe and Thomas Ross (1996). "Cooperation without Reputation. Experimental Evidence from Prisoner's Dilemma Games." Games and Economic Behavior 12: 187-218. 
Croson, Rachel T.A., Enrique Fatas and Tibor Neugebauer (2005). "Reciprocity, Matching and Conditional Cooperation in Two Public Goods Games." Economics Letters 87: 95-101.

Dufwenberg, Martin and Georg Kirchsteiger (2004). "A Theory of Sequential Reciprocity." Games and Economic Behavior 47: 268-298.

Dugan, Laura, Gary LaFree and Alex R. Piquero (2005). "Testing a Rational Choice Theory of Airline Hijackings." Criminology 43: 1031-1066.

Dunning, David, Dale W. Griffin, James D. Milojkovic and Lee Ross (1990). "The Overconfidence Effect in Social Prediction." Journal of Personality and Social Psychology 58: 568-581.

Eckel, Catherine C. and Philip J. Grossman (1996). "Altruism in Anonymous Dictator Games." Games and Economic Behavior 16: 181-191.

Eckel, Catherine C. and Philip J. Grossman (1998). "Are Women Less Selfish Than Men?: Evidence from Dictator Experiments." Economic Journal 108: 726-735.

Eide, Erling, Paul H. Rubin and Joanna M. Shepherd (2006). Economics of Crime. Boston, Now Publishers.

Ellsberg, Daniel (1961). "Risk, Ambiguity, and the Savage Axioms." Quarterly Journal of Economics 75: 643-669.

Engel, Christoph (2011). "Dictator Games. A Meta-Study." Experimental Economics 14: 583-610.

Engel, Christoph and Lilia Zhurakhovska (2012). When is the Risk of Cooperation Worth Taking? The Prisoner's Dilemma as a Game of Multiple Motives http://www.coll.mpg.de/pdf_dat/2012_16online.pdf.

ENGLERTH, MARKUS (2010). Der beschränkt rationale Verbrecher. Behavioral Economics in der Kriminologie. Münster, Lit.

FALK, ARMIN and URS FISCHBACHER (2006). "A Theory of Reciprocity." Games and Economic Behavior 54: 293-315.

Fehr, ERnst and Klaus M. Schmidt (1999). "A Theory of Fairness, Competition, and Cooperation." Quarterly Journal of Economics 114: 817-868.

FeHR, ERnst and Klaus M. Schmidt (2006). "The Economics of Fairness, Reciprocity and Altruism. Experimental Evidence and New Theories." Handbook on the Economics of Giving, Reciprocity and Altruism 1: 615-691. 
Fershtman, Chaim and Uri Gneezy (2001). "Discrimination in a Segmented Society. An Experimental Approach." Quarterly Journal of Economics 116: 351-377.

FISCHBACHER, URS (2007). "z-Tree. Zurich Toolbox for Ready-made Economic Experiments." Experimental Economics 10: 171-178.

FischBACHER, Urs and SimON GÄChTER (2010). "Social Preferences, Beliefs, and the Dynamics of Free Riding in Public Good Experiments." American Economic Review 100: $541-556$.

Fischbacher, Urs, Simon GÄChter and Ernst Fehr (2001). "Are People Conditionally Cooperative? Evidence from a Public Goods Experiment." Economics Letters 71: 397404.

Fong, Christina M. (2007). "Evidence from an Experiment on Charity to Welfare Recipients. Reciprocity, Altruism and the Empathic Responsiveness Hypothesis." Economic Journal 117: 1008-1024.

Fong, Christina M. and Erzo F.P. LutTMER (2009). "What Determines Giving to Hurricane Katrina Victims? Experimental Evidence on Racial Group Loyalty." American Economic Journal: Applied Economics 1: 64-87.

Frey, Bruno and Stephan Meier (2004). "Social Comparisons and Pro-social Behavior: Testing "Conditional Cooperation" in a Field Experiment." American Economic Review 94: 1717-1722.

Goette, Lorenz, David Huffman, Stephan Meier and Matthias Sutter (2010). Group Membership, Competition, and Altruistic versus Antisocial Punishment. Evidence from Randomly Assigned Army Groups http://www.econstor.eu/bitstream/10419/46117/1/658144294.pdf.

Grogger, JefFrey (1998). "Market Wages and Youth Crime." Journal of Labor Economics 16: $756-791$.

Güth, Werner, Rolf Schmittberger and Bernd Schwarze (1982). "An Experimental Analysis of Ultimatum Bargaining." Journal of Economic Behavior and Organization 3: 367-388.

Henrich, Joseph and Robert Boyd (2005). "'Economic Man' in Cross-Cultural Perspective. Behavioral Experiments in 15 Small-Scale Societies." Behavioral and Brain Sciences 28: $795-815$. 
Henrich, Joseph, Richard McElreath, Abigail Barr, JeAn Ensminger, Clark Barrett, Alexander Bolyanatz, Juan Camilo Cardenas, Michael Gurven, Edwins Gwako, Natalie Henrich, Carolyn lesorogol, Frank Marlowe, David Tracer and JoHn ZIKer (2006). "Costly Punishment across Human Societies." Science 312(5781): 1767-1770.

Hoffman, Elizabeth, Kevin McCabe, Keith Shachat and Vernon L. Smith (1994). "Preferences, Property Rights, and Anonymity in Bargaining Games." Games and Economic Behavior 7: 346-380.

Hoffman, Elizabeth, Kevin McCabe and Vernon L. Smith (1996). "Social Distance and Other-Regarding Behavior in Dictator Games." American Economic Review 86: 653660 .

Horney, Julie and Ineke Haen Marshall (1992). "Risk Perceptions Among Serious Offenders. The Role of Crime and Punishment." Criminology 30(4): 575-594.

Houser, Daniel and DANiEl Schunk (2009). "Social Environments With Competitive Pressure: Gender Effects in the Decisions of German Schoolchildren." Journal of Economic Psychology 30: 634-641.

Jacobs, Bruce A., Volkan Topalli and Richard W. Wright (2000). "Managing Retaliation. Drug Robbery and Informal Sanction Threats." Criminology 38(1): 171198.

Jacobsen, Karin J., Kari H. Eika, Leif Helland, Jo Thori Lind and Karine Nyborg (2011). "Are Nurses More Altruistic Than Real Estate Brokers?" Journal of Economic Psychology 32(5): 818-831.

KAHAN, DAN M. (2003). "Logic of Reciprocity. Trust, Collective Action, and Law, The." Michigan Law Review 102: 71-103.

Kahneman, Daniel, Jack L. Knetsch and Richard Thaler (1986). "Fairness and the Assumptions of Economics." Journal of Business 59: S285-S300.

Kahneman, Daniel and Amos Tversky (2000). Choices, Values, and Frames. Cambridge, Russell Sage Foundation; Cambridge University Press.

Keser, Claudia and Frans van Winden (2000). "Conditional Cooperation and Voluntary Contributions to Public Goods." Scandinavian Journal of Economics 102: 23-39.

Klepper, Steven and Daniel Nagin (1989). "The Deterrent Effect of Perceived Certainty and Severity of Punishment Revisited." Criminology 27(4): 721-746.

LAIBSON, DAVID (1997). "Golden Eggs and Hyperbolic Discounting." Quarterly Journal of Economics 112: 443-477. 
Leider, Stephen, Markus M. Möbius, Tanya Rosenblat and Quoc-Anh Do (2009). What Do We Expect from Our Friends?

https://mercury.smu.edu.sg/rsrchpubupload/15345/ExpectFriends.pdf.

Levitt, Steven D. (2004). "Understanding Why Crime Fell in the 1990s: Four Factors that Explain the Decline and Six that Do Not." Journal of Economic Perspectives 18: 163 190.

Levitt, Steven D. and Sudhir Alladi Venkatesh (2000). "An Economic Analysis of a Drug-selling Gang's Finances." Quarterly Journal of Economics 115(3): 755-789.

List, JoHN A. (2007). "On the Interpretation of Giving in Dictator Games." Journal of Political Economy 115: 482-493.

Loughran, Thomas A., Ray Paternoster, Alex R. Piquero and Jeffrey Fagan (2013). "“A Good Man Always Knows His Limitations". The Role of Overconfidence in Criminal Offending." Journal of Research in Crime and Delinquency ***.

Loughran, Thomas A., Ray Paternoster, Alex R. Piquero and Greg Pogarsky (2011). "On Ambiguity in Perceptions of Risk. Implications for Criminal Decision Making and Deterrence." Criminology 49(4): 1029-1061.

Loughran, Thomas A., Ray Paternoster and Douglas Weiss (2012). "Hyperbolic Time Discounting, Offender Time Preferences and Deterrence." Journal of Quantitative Criminology 28: 607-628.

Loughran, Thomas A., Kyle J. Thomas and Alex R. Piquero (2013). "Do Individual Characteristics Explain Variation in Sanction Risk Updating Among Serious Juvenile Offenders? Advancing the Logic of Differential Deterrence." Law and Human Behavior $* * *: * * *$.

MacDonald, ZiggY (2002). "Official Crime Statistics. Their Use and Interpretation." Economic Journal 112(477): F85-F106.

MCCARTHY, BILl (2002). "New Economics of Sociological Criminology." Annual Review of Sociology 28: 417-442.

McCarthy, Bill and John Hagan (2001). "When Crime Pays. Capital, Competence, and Criminal Success." Social Forces 79(3): 1035-1060.

Nagin, Daniel and Ray Paternoster (1991). "The Preventive Effects of the Perceived Risk of Arrest. Testing an Expanded Conception of Deterrence." Criminology 29(4): 561587.

NAGin, DANiEl and RAY PATERnOSTER (1993). "Enduring Individual Differences and Rational Choice Theories of Crime." Law and Society Review 27: 467-496. 
Nagin, Daniel and Ray Paternoster (1994). "Person Capital and Social Control. The Deterrence Implications of a Theory of Individual Differences in Criminal Offending." Criminology 32(4): 581-606.

Nagin, Daniel and Greg Pogarsky (2001). "Integrating Celerity, Impulsivity, and Extralegal Sanction Threats into a Model of General Deterrence. Theory and Evidence." Criminology 39: 865-892.

Nagin, Daniel S. and Greg Pogarsky (2001). "Integrating Celerity, Impulsivity, and Extralegal Sanction Threats into a Model of General Deterrence. Theory and Evidence." Criminology 39: 865-891.

Nagin, Daniel S. and Greg Pogarsky (2003). "An Experimental Investigation of Deterrence. Cheating, Self-Serving Bias, and Impulsivity." Criminology 41: 167-193.

Oosterbeek, Hessel, Randolph Sloof and Gijs VAn de Kuilen (2004). "Cultural Differences in Ultimatum Game Experiments. Evidence from a Meta-Analysis." Experimental Economics 7(2): 171-188.

Paternoster, Ray and Shawn D. Bushway (2008). "Desistance and the Feared Self. Toward an Identity Theory of Criminal Desistance." Journal of Criminal Law and Criminology 99: 1103-1156.

Paternoster, Ray, Linda Saltzmann, Theodore G. Chiricos and Gordon P. Waldo (1983). "Perceived Risk and Social Control. Do Sanctions Really Deter?" Law and Society Review 17: 457-479.

PATERnoster, Ray and SAlly Simpson (1996). "Sanction Threats and Appeals to Morality. Testing a Rational Choice Model of Corporate Crime." Law and Society Review 30: 549-583.

Piquero, Alex R., Lynn Langton and Zenta GomeZ-Smith (2004). "Discerning Unfairness Where Others May Not. Low Self-Control and Perceiving Sanctions as Unfair." Criminology 42: 699-734.

Piquero, Alex R., Ray Paternoster, Greg Pogarsky and Thomas A. Loughran (2011). "Elaborating the Individual Difference Component in Deterrence Theory." Annual Review of Law and Social Science 7: 335-360.

RABIN, MAtThew (1993). "Incorporating Fairness into Game Theory and Economics." American Economic Review 83: 1281-1302.

Rebellon, Cesar J., Nicole Leeper Piquero, Alex R. Piquero and Stephen G. Tibbetts (2010). "Anticipated Shaming and Criminal Offending." Journal of Criminal Justice 38(5): 988-997. 
Selten, ReINHARD (1967). Die Strategiemethode zur Erforschung des eingeschränkt rationalen Verhaltens im Rahmen eines Oligopolexperiments. Beiträge zur experimentellen Wirtschaftsforschung. E. Sauermann. Tübingen, Mohr: 136-168.

SElten, ReInHARD (1998). "Features of Experimentally Observed Bounded Rationality." European Economic Review 42: 413-436.

Small, Deborah and George Loewenstein (2003). "Helping a Victim or Helping the Victim. Altruism and Identifiability." Journal of Risk and Uncertainty 26(5-16).

SMith, VERnON L. (1965). "Experimental Auction Markets and the Walrasian Hypothesis." Journal of Political Economy 73: 387-393.

Smith, Vernon L. (1976). "Experimental Economics: Induced Value Theory." American Economic Review Papers and Proceedings 66: 274-279.

Smith, Vernon L., Arlington W. Williams, W. Kenneth Bratton and Michael G. VANNONI (1982). "Competitive Market Institutions. Double Auction vs. Sealed BidOffer." American Economic Review 72: 58-77.

SOBEL, JOEL (2005). "Interdependent Preferences and Reciprocity." Journal of Economic Literature 43: 392-436.

VAN DER MERWe, WiLhelm Gerhard and Justine Burns (2008). "What's in a Name? Racial Identity and Altruism in Post-Apartheid South-Africa." South African Journal of Economics 76: 266-275.

Zamir, Eyal and Ilana Ritov (2012). "Loss Aversion, Omission Bias, and the Burden of Proof in Civil Litigation." Journal of Legal Studies 41(1): 165-207. 


\section{Appendix}

\section{Decision Screens}

The experiment was computerized. In the first experiment, participants on a screen saw the following question:

"How many experimental currency units do you want to transfer to another randomly selected participants, who is in this room?

(You can choose between 0 and 10 currency units)"

It was orally explained to participants that each experimental currency unit was worth 50 Cents.

In the first part of the second experiment, the same screen was used. In the second part of this experiment, the screen read

"How many experimental currency units do you want to transfer to the charity 'Brot für die Welt'?

(You can choose between 0 and 10 currency units)" 


\section{Preprints 2013}

2013/04: Fischer S., Goerg S. J., Hamann H., Cui Bono, Benefit Corporation? An Experiment Inspired by Social Enterprise Legislation in Germany and the US

2013/03: Hakenes H., Schnabel I., Bank Bonuses and Bail-Outs

forthcoming in: Journal of Money, Credit, and Banking, In Press.

2013/02: Ding J., Nicklisch A., On the Impulse in Impulse Learning

2013/01: Engel C., Behavioral Law and Economics: Empirical Methods

\section{Preprints 2012}

2012/23: Engel C., Neglect the Base Rate: It's the Law!

2012/22: Kuhle W., The Dynamics of Utility in the Neoclassical OLG Model

2012/21: Schweizer M., Comparing Holistic and Atomistic Evaluation of Evidence

2012/20: Bouton L., Castanheira M., Llorente-Saguer A., Divided Majority and Information Aggregation: Theory and Experiment

2012/19: Goerg S. J., Kube S., Goals (th)at Work - Goals, Monetary Incentives, and Workers' Performance

2012/18: Lüdemann J., Öffentliches Wirtschaftsrecht und ökonomisches Wissen, Bonn, Max Planck Institute for Research on Collective Goods, 2012. Full textapplication/pdf icon

forthcoming in: Extrajuridisches Wissen im Verwaltungsrecht. Analysen und Perspektiven, Tübingen, Mohr Siebeck, In Press.

2012/17: Cornelißen T., Himmler O., Koenig T., Fairness Spillovers - The Case of Taxation

2012/16: Engel C., Zhurakhovska L., When is the Risk of Cooperation Worth Taking? The Prisoner's Dilemma as a Game of Multiple Motives

2012/15: Altmann S., Traxler C., Nudges at the Dentist

2012/14: Lang M., Contracting with Subjective Evaluations and Communication

2012/13: Engel C., Moffat P. G., Estimation of the House Money Effect Using Hurdle Models, 2012

2012/12: Hortala-Vallve R., Llorente-Saguer A., Nagel R., The Role of Information in Different Bargaining Protocols forthcoming in: Experimental Economics, In Press.

2012/11: Bade S., Serial Dictatorship: the Unique Optimal Allocation Rule when Information is Endogenous

2012/10: Buch C. M., Engel C., The Tradeoff Between Redistribution and Effort: Evidence from the Field and from the Lab 2012/09: Stürmer M., Schwerhoff G., Non-Renewable but Inexhaustible - Resources in an Endogenous Growth Model 2012/08: Engel C., Hamann H., The Hog-Cycle of Law Professors

2012/07: Eisenberg T., Engel C., Assuring Adequate Deterrence in Tort: A Public Good Experiment 2012/06: Ding J., A Portfolio of Dilemmas: Experimental Evidence on Choice Bracketing in a Mini-Trust Game 2012/05: Admati A. R., DeMarzo P. M., Hellwig M., Pfleiderer P., Debt Overhang and Capital Regulation (coming soon) 2012/04: Engel C., Low Self-Control As a Source of Crime. A Meta-Study

2012/03: Casella A., Llorente-Saguer A., Palfrey T. R., Competitive Equilibrium in Markets for Votes

2012/02: Engel C., Harm on an Innocent Outsider as a Lubricant of Cooperation - An Experiment,

2012/01: Engel C., Goerg S. J., Yu G., Symmetric vs. Asymmetric Punishment Regimes for Bribery 